\title{
VEGETAÇÃO ARBÓREA DO CAMPUS DA UNIVERSIDADE DE PASSO FUNDO
}

\author{
Evanisa Fátima Reginato Quevedo Melo”, Branca Maria Aimi Severo²
}

\begin{abstract}
RESUMO
A paisagem reconstruída e interpretada em uma vegetação urbana como no Campus I da Universidade de Passo Fundo pode ser uma obra de arte e um desafio para torná-la percebida pelos cinco sentidos. Importante área verde regional, nela foi introduzida a vegetação que a caracteriza, na busca da relação harmônica entre o ambiente construído e o meio natural. O objetivo foi conhecer, identificar, localizar, catalogar, conservar e divulgar o valor da preservação da vegetação desta área, bem como proporcionar à comunidade a sensibilização quanto à flora, ao meio ambiente e à melhoria da qualidade de vida, aliada à responsabilidade social da Universidade. A área foi subdividida em setores, considerando-se como ponto de referência os prédios das Unidades ou de Serviços, além de ruas e avenidas. As espécies catalogadas foram localizadas na planta-baixa do Campus. Foi aplicado o sistema de varredura, amostrando os exemplares com DAP igual ou maior a $10 \mathrm{~cm}$. As espécies foram fotografadas e as exsicatas arquivadas no Herbário da Universidade de Passo Fundo (RSPF). A vegetação é composta por mais de três mil exemplares de 108 espécies botânicas em 35,5ha. Há predomínio de espécies exóticas como eucaliptos, pinus, ciprestes, grevilhas, entre outras. Destacam-se pelo porte, beleza e colorido de suas flores, espécies nativas como ipês, corticeira, canafístula, chuva-de-ouro, pinheiro brasileiro e outros. O espaço representa uma coleção de espécies de valor ornamental, madeirável, medicinal e frutífero, crescendo em número e biodiversidade, buscando a sustentabilidade de todo o complexo, resgatando a cultura, a educação e a história. O Campus apresenta uma vegetação exuberante, densa e colorida, garantindo plasticidade e beleza cênica à área, como um laboratório vivo para ensino, pesquisa e extensão, assim como à comunidade e aos visitantes, agregando valor social, contribuindo para a melhoria da qualidade de vida e para a transformação da paisagem urbana.
\end{abstract}

Palavras-chave: vegetação urbana, campus, biodiversidade, paisagismo.

\footnotetext{
${ }^{1}$ Eng. Florestal e Agrônoma, Prof. Faculdade de Engenharia e Arquitetura/UPF; Passo Fundo/RS evanisa@upf.br

${ }^{2}$ Bióloga, Prof. Instituto de Ciências Biológicas/UPF; Passo Fundo/RS branca@upf.br
} 


\title{
ARBORIST VEGETATION OF THE UNIVERSITY OF PASSO FUNDO'S CAMPUS
}

\begin{abstract}
The reconstructed and interpreted landscape on urban vegetation as in Campus I from the University of Passo Fundo could be work of art and challenge to recognize it by the five senses. Being an important regional green spot, it was introduced a characteristic vegetation, searching a harmonic relationship between the natural and the constructed environment. The goal was to know, to identify, to locate, to catalog, to keep, to spread the preservation's value of this area, to touch the community about the flora and the environment, and the improvement on the quality of life, allied to the University's social responsibilities. The area was divided in sectors, using as reference buildings, streets and avenues. The cataloged species were located on the Campus's map. The inventory gathered samples with DAP equal or larger than $10 \mathrm{~cm}$. The species were photographed and the samples were filed in the University's herbarium. The arborist vegetation consists in more than three thousand exemplary of one hundred and twelve botanical species in 35,5 square yards. Exotic species like Eucalyptus, Pinus, Cupressus, Grevillea among others are predominant. Native species like Tabebuia, Erythrina, Peltophorum, Senna, are noticed by its size, beauty and the vivid colors of the flowers. The place represents a high value ornamental collection, is useful as timber, has medicinal purposes and as fruit trees, growing in numbers and biodiversity, seeking the self-support of the whole structure, recovering the culture, education and history. The Campus shows exuberant vegetation, dense and colorful, which guarantees a plasticity and beauty of the area, as a live laboratory to educate, further researching, as well to the community and visitors, adding social value and contributing to a better quality of life and to transformation of the urban landscape.
\end{abstract}

Key words: urban vegetation, campus, biodiversity, landscape. 


\section{INTRODUÇÃO}

A paisagem reconstruída e interpretada em uma vegetação urbana como no Campus I da Universidade de Passo Fundo pode ser uma obra de arte que desafia a administração para torná-la percebida pelos cinco sentidos dos usuários. Por tratar-se de importante área verde regional, neste espaço foram introduzidas às espécies arbóreas que hoje o caracterizam, com rica e diversificada vegetação, resultado da busca da relação harmônica entre o ambiente construído e o meio natural, ao longo dos seus 40 anos. A necessidade do aumento da área construída, em função do crescimento acadêmico e conseqüente expansão física, tem alterado a fisionomia da área central deste espaço, por onde circulam grande número de pessoas e de veículos. A preocupação com o entorno da massa construída tem sido um trabalho complementar, paralelo e constante.

A utilização de plantas ornamentais com o intuito paisagístico, como composição cênica ou de destaque/realce de estruturas e ambientes vem, com o passar dos anos, aliando-se a aspectos funcionais da utilização desta mesma vegetação com múltiplos objetivos. Á arte do belo, à estética e à forma, agrega-se o aspecto funcional, a simbiose entre o objetivo e o objeto, em que o foco vem a ser a melhoria da qualidade de vida da população (ANGELIS NETO e ANGELIS, 1999).

Hoje, um dos principais desafios é interromper o processo de degradação ambiental nas áreas urbanas. Neste sentido, a criação, a recuperação, a qualificação (ou requalificação) dos espaços públicos e de convivência, são fundamentais a sustentabilidade, à valorização da paisagem, à parceria entre instituições públicas e privadas, assim como à melhoria das condições de conforto ambiental. A presença de áreas verdes, urbanas ou não, tem sido objeto de estudos por diferentes grupos e instituições, desde o simples levantamento e mapeamento de espécies (RODRIGUES e GANDOLFI, 1996; GONÇALVES et al., 1998; CARDOSO-LEITE et al,. 1999; MEDEIROS et al.,1999), ou a identificação das espécies com enfoque na educação ambiental, ou trilha ecológica (DIAS et al., 1999; FÁVERO et al.,1999), até o resgate do papel social da vegetação para o bem-estar do homem e a melhoria da qualidade de vida (ROCHA e AGRA, 1998; MARENZI, 1999).

Independente da beleza intrínseca reconhecida na vegetação que faz parte das áreas verdes, o tratamento paisagístico pode melhorar a composição estética da paisagem urbana, cumprindo sua missão de plano estético acoplando a relação homem-natureza (FAMURS, 2000).

O discurso ambiental alimenta o mito da natureza intocada pelo homem e, até mesmo na atualidade, a sustentabilidade do ambiente urbano promove discussões quanto ao papel que the cabe. A crise ambiental planetária atinge em cheio o homem em suas diversas esferas. 
Assim, a qualificação sócio-econômica-ambiental fomenta a manutenção, a preservação e a conservação dos recursos naturais $s$ paisagem de um Campus universitário, propiciando o exercício da cidadania.

A floresta urbana deve satisfazer as necessidades da comunidade, tanto no que tange a lazer, recreação, conhecimento, alimentação, quanto à exploração econômica. Para preservá-la, é necessário conhecê-la e divulgar sua composição e propriedades. O Campus I da UPF historicamente tem servido de espaço socio-cultural para a comunidade de Passo Fundo e região. Segmentos da UPF e da comunidade têm buscado freqüentemente informações e referências, usando este patrimônio natural e cultural como meio de educação interativa, fortalecendo as relações existentes entre o meio antrópico e o meio natural.

A pesquisa foi realizada com o objetivo de conhecer, identificar, localizar, catalogar, conservar e divulgar o valor da preservação das espécies arbóreas do Campus I da UPF, bem como proporcionar à comunidade a oportunidade de nova postura perante a vegetação, sensibilizando-a quanto à importância da flora, ao meio ambiente e à melhoria da qualidade de vida, aliada à responsabilidade social da Universidade.

\section{METODOLOGIA}

\section{Área de Estudo}

O trabalho foi desenvolvido na área física do Campus I da Universidade de Passo Fundo (28ำ15' S e 52ํ1' W, com altitude de $687 \mathrm{~m}$ snm), localizada no Bairro São José, junto à BR 285, no município de Passo Fundo/RS, limitada à área compreendida entre os pontos: BR 285, cerca limítrofe junto à Estrada Trigo, a parte frontal do Hospital de Olhos Diógenes Martins Pinto e a rua paralela à frente da FEAR.

O trabalho de laboratório foi desenvolvido nas dependências do Museu Zoobotânico Augusto Ruschi (Muzar) e a documentação dos exemplares (exsicatas) foi arquivada no Herbário da Universidade de Passo Fundo (RSPF).

\section{Inventário, Identificação e Localização}

As áreas arborizadas foram inventariadas, pelo sistema de varredura, sendo amostrados os exemplares com DAP (diâmetro a altura do peito) igual ou maior de 0,10 m. Foi colhida uma amostra (exsicata) para a identificação e arquivamento, a fim de serem documentados e permitirem intercâmbio com instituições similares.

As árvores foram localizadas nos mapas específicos de cada área e os exemplares foram fotografados para registro e documentação. A identificação foi feita com auxílio de 
lupa, consultas a obras de autores da área (LONGHI, 1995; LORENZI, 1992; REITZ et al., 1988), comparação com exemplares já arquivados ou consulta a especialistas.

\section{RESULTADOS E DISCUSSÃO}

A área escolhida para ser o Campus I da UPF foi, originalmente, uma área de uso agrícola. Porém, ao longo de sua história, teve implantada uma coleção ímpar de exemplares arbóreos, tanto nativos quanto exóticos.

A expansão da área construída, aliada às administrações e a contribuição dos usuários alteraram a paisagem natural. A diversidade vegetal da área compreendem mais de 3 mil indivíduos permitindo diversas composições paisagísticas, com 108 espécies botânicas.

A história do crescimento e desenvolvimento da UPF perpassa pelo crescimento regional e de sua população, marcada pelas gerações de acadêmicos que obtiveram seus títulos de formação superior, deixando, materializado no próprio Campus, a sua passagem, com plantio de árvores. Em outras instituições semelhantes esta preocupação com o ambiente e sua relação com a comunidade também tem acontecido (PIVETTA et al., 2001).

O plantio de araucárias(Figura 1), isoladas ou formando maciços homogêneos resgata a cultura, a educação e a história, salvaguardando a vegetação característica regional nativa e preservando-a, visto que encontra-se nas listas de espécies ameaçadas. Esta espécie, tradicionalmente de valor econômico, alimentou, por mais de 150 anos, a indústria madeireira do sul (EMBRAPA, 1996) e hoje tem mais de 210 exemplares preservados neste espaço, correspondendo a $6,12 \%$ da sua vegetação arbórea total. A diversidade e a exuberância da vegetação do Campus garante plasticidade e beleza cênica à área.
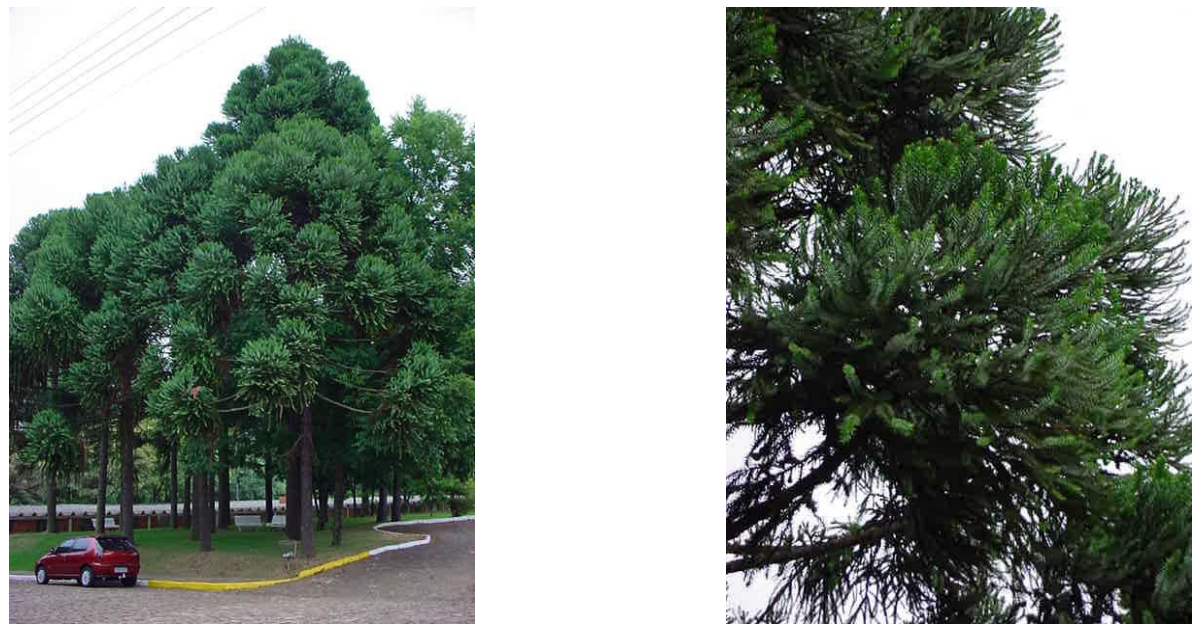

Figura 1. Bosque com predominância de araucárias e detalhe de ramo de Araucaria angustifolia . 
A vegetação é considerada um verdadeiro laboratório vivo para aulas práticas da educação formal e informal, em cursos de graduação ou de pós-graduação da UPF, além de servir ao uso dos diferentes segmentos de ensino público ou privado. De acordo com os parâmetros curriculares nacionais (MEC, 1997), no meio ambiente, em termos educativos, vários temas podem ser estudados. As visitas a áreas naturais podem e devem ser feitas da pré-escola à Universidade, procurando a perfeita integração.

A composição arbórea do ambiente promove benefícios na condição climática, na redução da poluição atmosférica, na redução da velocidade dos ventos, na melhoria das condições do solo, no aumento da diversidade e quantidade da fauna (especialmente de pássaros), na melhoria das condições acústicas (diminuindo a poluição sonora), criando opções de recreação e lazer (MENEGAT, 1998). A presença de vegetação no Campus I desencadeia a percepção das sutis relações das formas, texturas e cores, na valorização estética das espécies e de sua associação com a paisagem criada, num desafio à sensibilidade.

A presença da floresta urbana do Campus traz qualidade de vida a seus estudantes, bem como à população em geral, já que a área é usada como espaço de lazer, principalmente aos fins-de-semana, uma vez que, o núcleo urbano do município não dispõe de áreas semelhantes. Plantando as espécies que melhor se adaptam à região e fazendo manutenção de forma correta, a vegetação do Campus pode contribuir para a melhoria da qualidade de vida dos usuários da área, por longo período, comprometendo-os com a responsabilidade social em relação a sua preservação e conservação.

O tratamento paisagístico de uma área é um patrimônio, pois o convívio harmonioso entre a população e o verde pode melhorar a composição estética e climática da paisagem. Deve ser estabelecido um sistema multidimensional, integrado e dinâmico de coleta, tratamento, arquivo, manutenção e operação de um conjunto de indicadores ambientais, devidamente parametrizados, que permitam avaliar sistematicamente a qualidade de vida que os espaços oferecem a seus usuários. Devem ser incluídas, no planejamento, ações de conservação e ou minimização de danos ambientais diagnosticados pelo sistema, o qual deverá fornecer os subsídios necessários para a recuperação do meio, além de avaliar a eficácia das mesmas (HARDT, 1994).

A manutenção de uma adequada relação entre a área verde e a população é particularmente importante nas metrópoles modernas, uma vez que as praças e parques incorporam novas funções dentro do organismo urbano. Além das funções tradicionais, as áreas verdes amenizam os efeitos da excessiva impermeabilização do solo e da supressão da vegetação provocados pela progressiva densificação das regiões metropolitanas (MENEGAT, 1998). Os parques e praças são componentes primordiais na composição da paisagem urbana, disponibilizando aos habitantes das cidades as alternativas mais 
democráticas de lazer ativo e passivo. Todos esses fatores transformaram as áreas verdes em elementos vitais para a construção de um espaço saudável, contribuindo significativamente para a melhoria da qualidade de vida dos cidadãos. Desta forma, a vegetação do Campus, além de local para a prática de lazer ativo e passivo, desperta nos usuários a consciência ambientalista, através da interpretação da natureza e da vivência em áreas mais preservadas e com biodiversidade paisagística.

A vegetação arbórea considerada nos diferentes espaços foi quantificada em função da sua ocorrência nos diversos ambientes (Tabela 1) demonstrando a diversidade de espécies e número de exemplares.

Tabela 1. Composição arbóreas do Campus I da UPF, em diversos ambientes, Passo Fundo, RS, 2003.

\begin{tabular}{|c|c|c|}
\hline Espaço físico & Número de exemplares & Quantidade de espécies \\
\hline Quadra A & 314 & 22 \\
\hline Quadra B & 298 & 36 \\
\hline Quadra C & 240 & 34 \\
\hline Quadra D & 608 & 62 \\
\hline Quadra E & 363 & 21 \\
\hline Quadra F & 1155 & 34 \\
\hline Quadra G & 109 & 29 \\
\hline Quadra H & 09 & 04 \\
\hline Quadra I & 25 & 02 \\
\hline Quadra J & 184 & 30 \\
\hline Quadra N & 32 & 06 \\
\hline Canteiro 1 & 23 & 11 \\
\hline Canteiro Agronomia & 05 & 02 \\
\hline $\begin{array}{l}\text { Avenida Educação Física e } \\
\text { ICB }\end{array}$ & 12 & 01 \\
\hline Avenida FAC e Direito & 40 & 01 \\
\hline $\begin{array}{c}\text { Avenida Agronomia e } \\
\text { Zoológico }\end{array}$ & 01 & 01 \\
\hline Avenida FEAR e Mecânica & 11 & 04 \\
\hline Entrada Oeste & 274 & 18 \\
\hline
\end{tabular}

Analisando as Quadras B, C, D e J (por exemplo) percebe-se que o número de espécies botânicas é sempre superior a 30. Por outro lado, a Quadra F concentra o maior número total de indivíduos, por tratar-se de uma área sem edificações e com a função de 
barreira acústica, junto a uma BR (estrada federal), onde ocorre concentração de eucaliptos, araucárias, ciprestes e grevilhas.

Considerando somente a Área E (como exemplo), constituída pela casa dos motoristas e elo de ligação entre a biblioteca central, estacionamento dos ônibus e o prédio da Engenharia (Tabela 2), é utilizada como área de passagem, contemplação e lazer. O eucalipto tem a função de quebra-vento, redução da poluição acústica, pelo seu porte e número de indivíduos. Já o umbu atua como ponto focal sendo um componente plástico e histórico-cultural, representativo da vegetação regional. Os plátanos formam uma alameda caracterizando a sazonalidade da vegetação e o colorido das flores é proporcionado por ipês, jacarandá, grevilha, tipuana, canafístula e chuva de ouro, numa seqüência de florescimento.

Tabela 2. Relação das espécies arbóreas da Área E do Campus I da UPF, 2003.

\begin{tabular}{|l|l|l|c|}
\hline \multicolumn{1}{|c|}{ Nome popular } & \multicolumn{1}{|c|}{ Nome científico } & \multicolumn{1}{c|}{$\begin{array}{c}\text { Total de } \\
\text { exemplares }\end{array}$} \\
\hline Álamo branco & Populus alba & Salicaceae & 02 \\
\hline Angico & Parapiptadenia rigida & Mimosaceae & 21 \\
\hline Aroeira vermelha & Schinus terebintifolius & Anacardiaceae & 01 \\
\hline Canafístula & Peltophorum dubium & Caesalpinaceae & 10 \\
\hline Canjerana & Cabralea canjerana & Sapindaceae & 03 \\
\hline Cedro & Cedrella fissilis & Meliaceae & 01 \\
\hline Chuva de ouro & Senna multijuga & Caesalpinaceae & 02 \\
\hline Cinamomo & Melia azedarach & Meliaceae & 08 \\
\hline Cipreste & Cupressus sempervirens & Cupressaceae & 10 \\
\hline Eucalipto & Eucalyptus sp & Myrtaceae & 256 \\
\hline Gerivá & Syagrus romanzoffiana & Aracaceae & 01 \\
\hline Grevilha robusta & Grevillea robusta & Proteaceae & 05 \\
\hline Ipê da serra & Tabebuia alba & Bignoniaceae & 02 \\
\hline Ipê amarelo & Tabebuia chrysotricha & Bignoniaceae & 22 \\
\hline Ipê roxo & Tabebuia avelanedae & Bignoniaceae & 10 \\
\hline Jacarandá & Jacaranda mimosefolia & Bignoniaceae & 01 \\
\hline Pinus & Pinus elliottii & Pinaceae & 08 \\
\hline Plátano & Platanus occidentalis & Platanaceae & 15 \\
\hline Tipa & Tipuana tipu & Fabaceae & 01 \\
\hline Umbu & Phytolacca dioica & Phytolacaceae & 02 \\
\hline & & Total de exemplares & 363 \\
\cline { 2 - 4 } & Total de espécies & 21 \\
\hline & & & \\
\hline
\end{tabular}

A presença de mais de 100 espécies arbóreas, distribuídas nas diferentes quadras e avenidas (algumas, na Tabela 3) ocorrem isoladas, em grupos ou em grande concentrações 
de vegetação arbórea, tomando a forma de bosques monoespecíficos e homogêneos ou com maior biodiversidade.

A preservação de espécies como a corticeira do banhado e a corticeira da serra, após intensa exploração comercial e presentes nas listas de espécies ameaçadas, valoriza e enriquece a vegetação do Campus, com o colorido de suas flores e para a atração da avifauna. A divulgação da composição vegetal e o valor atribuído pela comunidade contribuem para a preservação de espécies, especialmente da araucária, das canelas e do açucará, representantes da Mata Ombófila Mista com Araucária, típica da região.

Um dos direitos do homem é o direito a um ambiente natural sadio e equilibrado. Assim, a paisagem do Campus se destaca pela riqueza de espécies arbóreas vegetais de diferentes origens, como as exóticas (eucaliptos, grevilha, ciprestes, tipuana, plátanos, e pinus) e seus respectivos valores etnobotânicos, que se adaptaram às condições climáticas locais, integrando-se com as espécies brasileiras, as nativas (ipês, corticeiras, canafistula, gerivá, umbu e pinheiro brasileiro). Esta convivência demonstra a propriedade da diversidade de exemplares podendo-se explorar seus benefícios sob diversos aspectos e demonstrar que é possível trabalhar as variações que envolvem a vegetação e a sustentabilidade de uma área que representa a cultura, a história e a biodiversidade, bem como contribuindo para a saúde física e mental dos usuários.

A composição vegetal representa uma coleção de espécies de valor ornamental, madeirável, medicinal e frutífero, pois ao longo dos anos vem crescendo em número e diversidade, buscando a sustentabilidade de todo o complexo, cumprindo a sua vocação social e de melhoria da qualidade de vida.

\section{CONCLUSÕES}

A interligação dos componentes naturais face ao processo de interferência antrópica coloca em alerta a necessidade de cuidados desta vegetação.

A universidade atuando como disseminadora de idéias e posturas relacionadas ao ambiente e à sociedade, pode usar sua área como demonstrativo nas ações conscientizadoras e na valorização do ambiente visual e natural, nos aspectos cognitivos, sensitivos e atitudinais, além de referência e estímulo para a transformação da paisagem urbana. 
Tabela 3. Principais espécies arbóreas utilizadas na arborização do Campus I da UPF.

\begin{tabular}{|c|c|c|c|c|}
\hline Nome popular & Nome científico & Família & $\begin{array}{l}\text { Cor/ } \\
\text { flor* }\end{array}$ & Folha** \\
\hline \multicolumn{5}{|c|}{ Nativas } \\
\hline Açoita-cavalo & Luhea divaricata & Tiliaceae & B & $\mathrm{D}$ \\
\hline Angico & Parapiptadenia rigida & Mimosaceae & B & D \\
\hline Araça & Psidium cattleianum & Myrtaceae & B & $P$ \\
\hline Araucária & Araucaria angustifolia & Araucariaceae & VE & $P$ \\
\hline Canafístula & Peltophorum dubium & Caesalpinaceae & $A$ & $\mathrm{D}$ \\
\hline Carobá & Jacaranda micrantha & Bignoniaceae & AV & $\mathrm{D}$ \\
\hline Cedro & Cedrella fissilis & Meliaceae & $B$ & $\mathrm{D}$ \\
\hline Cerejeira & Eugenia involucrata & Myrtaceae & $\mathrm{B}$ & SD \\
\hline Chuva-de-ouro & Senna multijuga & Caesalpinaceae & A & $\mathrm{D}$ \\
\hline Corticeira & Erythrina crista-gali & Fabaceae & V & $\mathrm{D}$ \\
\hline Corticeira da Serra & Erythrina falcata & Fabaceae & L & $\mathrm{D}$ \\
\hline Erva-mate & Ilex paraguariensis & Aquifoliaceae & $B$ & $\mathrm{P}$ \\
\hline Falso barbatimão & Cassia leptophylla & Caesalpinaceae & A & SD \\
\hline Gerivá & Syagrus romanzoffiana & Aracaceae & A & $P$ \\
\hline Guabiju & Myrcianthes pungens & Myrtaceae & B & SD \\
\hline Guabiroba & $\begin{array}{l}\text { Campomanesia } \\
\text { xanthocarpa }\end{array}$ & Myrtaceae & B & SD \\
\hline Ipê amarelo & Tabebuia chrysotricha & Bignoniaceae & A & D \\
\hline Ipê da Serra & Tabebuia alba & Bignoniaceae & A & $\mathrm{D}$ \\
\hline Ipê roxo & Tabebuia avelanedae & Bignoniaceae & $\mathrm{R}$ & $\mathrm{D}$ \\
\hline Manduirana & Senna macranthera & Caesalpinaceae & A & SD \\
\hline Paineira & Chorisia speciosa & Bombacaceae & $\mathrm{R}$ & $\mathrm{D}$ \\
\hline Pitangueira & Eugenia uniflora & Myrtaceae & B & SD \\
\hline Quaresmeira & Tibouchina sellowiana & Melastomataceae & $\mathrm{RV}$ & $P$ \\
\hline Timbaúva & $\begin{array}{l}\text { Enterolobium } \\
\text { contortisiliquum }\end{array}$ & Mimosaceae & B & $\mathrm{D}$ \\
\hline Umbu & Phytolacca dioica & Phytolacaceae & $B$ & $\mathrm{D}$ \\
\hline \multicolumn{5}{|c|}{ Exóticas } \\
\hline Cinamomo & Melia azedarach & Meliaceae & AV & $\mathrm{D}$ \\
\hline Eucalipto & Eucalyptus sp & Myrtaceae & $B$ & $P$ \\
\hline Extremosa & Lagertroemia indica & Litraceae & $\mathrm{R}, \mathrm{B}$ & $\mathrm{D}$ \\
\hline Grevilha robusta & Grevillea robusta & Proteaceae & $\mathrm{AL}$ & $P$ \\
\hline Jacarandá & Jacaranda mimosefolia & Bignoniaceae & AV & $\mathrm{D}$ \\
\hline Pinus & Pinus sp & Pinaceae & VE & SD \\
\hline Plátano & Platanus sp & Platanaceae & VE & D \\
\hline Tipa & Tipuana tipa & Fabaceae & A & $\mathrm{D}$ \\
\hline Uva do Japão & Hovenia dulcis & Rhamnaceae & $B$ & $\mathrm{D}$ \\
\hline
\end{tabular}

Legenda:

${ }^{*}$ Cor da flor $-A=$ amarela, $A L=$ amarelo laranja, $A V=$ azul violáceo, $B=$ branca, $L=L$ aranja,

$R=$ róseo, $R V=$ róseo-violáceo $V=$ vermelha, $V E=$ verde

${ }^{* *}$ Folha $-D=$ decídua,$P=$ perene, $S P=$ semi-decídua 


\section{REFERÊNCIAS BIBLIOGRÁFICAS}

ANGELIS NETO, G; ANGELIS, B.L.D. de Plantas ornamentais: do paisagismo a outras aplicações. Rev. Bras. Hortc. Ornam. , Campinas, v.5, n.1, p.12-19, 1999.

CARDOSO-LEITE, Eliana et al. Mapeamento da Vegetação de uma Reserva Biológica no Sudeste do Brasil, Através de Fotointerpretação e Levantamento de Campo, Como Subsídio ao seu Zoneamento e Conservação. In: CONGRESSO NACIONAL DE BOTÂNICA, 50, 1999, Blumenau/SC. Programa e Resumos... Blumenau: Soc. Bot. Br., 1999. p. 149.

DIAS, Adriana et al. Programa piloto de Educação Ambiental na trilha do Jacatirão, Ilha de Santa Catarina, Florianópolis. In: CONGRESSO NACIONAL DE BOTÂNICA, 50, 1999, Blumenau/SC. Programa e Resumos... Blumenau: Soc. Bot. Br., 1999. p. 151.

EMBRAPA. Atlas do meio ambiente do Brasil. Brasília: Ministério da Agicultura, do Abastecimento e da Reforma Agrária., 1996.

FAMURS. Orientações básicas para manejo da arborização urbana: Planejamento e educação ambiental. Porto Alegre : FAMURS , 2000. 104p.

FÁVERO, Oriana A. et al. Elaboração de Roteiro Ecoturístico para a Trilha da Pedra Santa, Floresta Nacional DIAS, Adriana et al. Programa piloto de Educação Ambiental na trilha do Jacatirão, Ilha de Santa Catarina, Florianópolis. In: CONGRESSO NACIONAL DE BOTÂNICA, 50, 1999, Blumenau/SC. Programa e Resumos... Blumenau: Soc. Bot. Br., 1999. p. 151.

GONÇALVES, Fábio Christiano C. et al. Análise Pós-Ocupação de uma Praça de Burle Marx em Recife. In: CONGRESSO NACIONAL DE BOTÂNICA, 49, 1998, Salvador/BA. Resumos... Salvador: Soc. Bot. Br., 1998. p. 265.

HARDAT, L. P.A. Áreas verdes como meio de recuperação de áreas degradadas urbanas. In: SIMPÓSIO SUL-AMERICANO E SIMPÓSIO NACIONAL RECUPERAÇÃO DE ÁREAS DEGRADADAS, 1994, Curitiba. Anais... Curitiba: FUPEF, 1994. p.173-184.

LONGHI, R. A. Livro das árvores: árvores do sul do Brasil. Porto Alegre : L\&PM, 1995. $176 p$. 
LORENZI, H . Árvores brasileiras. Nova Odessa: Ed. Plantarum, 1992. 352p.

MARENZI, Rosemeri Carvalho. A influência da Vegetação nas Preferências Paisagísticas no Município da Penha. In: CONGRESSO NACIONAL DE BOTÂNICA, 50, 1999, Blumenau/SC. Programa e Resumos... Blumenau: Soc. Bot. Br., 1999. p. 150.

MEDEIROS, João de Deus et al. A Vegetação do Parque Florestal do Rio Vermelho. In: CONGRESSO NACIONAL DE BOTÂNICA , 50, 1999, Blumenau/SC. Programa e Resumos... Blumenau: Soc. Bot. Br., 1999. p.150.

MENEGAT, Rivaldo (coordenador). Atlas ambiental de Porto Alegre. Porto Alegre: Ed. Universidade - UFRGS, 1998, 237 pgs.

MINISTÉRIO DE EDUCAÇÃO DO BRASIL.Secretaria de Educação Fundamental. Parâmetros Curriculares Nacionais : Meio Ambiente e Saúde. Brasília. 1997

PIVETTA, K.F.L. et al. Estudo de remodelação do jardim do prédio da administração da Faculdade de Ciências Agrárias e Veterinárias - UNESP, Campus de Jaboticabal, SP. In: ENCONTRO NACIONAL DE ARBORIZAÇÃO URBANA, 9, 2001, Brasília/DF. Resumos... Brasília: SBAU, 2001. p. 99

REITZ, R.; KLEIN, R.M.; REIS, A. Projeto madeira do Rio Grande do Sul. Porto Alegre : Herbário Barbosa Rodrigues e Secretaria da Agricultura do Rio Grande do Sul, 1988. 525p.

ROCHA, Emerson A. e AGRA, Maria de F. Cactaceae Medicinais da Paraíba, Brasil. In: CONGRESSO NACIONAL DE BOTÂNICA, 49, 1998, Salvador/BA. Resumos... Salvador: Soc. Bot. Br., 1998. p. 285.

RODRIGUES, R.R.; GANDOLFI, S. Recomposição de florestas nativas: princípios gerais e subsídios para uma definição metodológica. Revista Brasileira de Horticultura Ornamental, Campinas, v.2, n.1, p. 4-15, 1996. 